\title{
Dampak Gaya Kepemimpinan Kepala Sekolah pada Kepuasan Pekerjaan Guru dan Motivasi Kerja
}

\author{
Eko Solihin ${ }^{*}$, Muhammad Giatman ${ }^{2}$, Ernawati ${ }^{3}$ iD \\ 1,2,3 Jurusan Universitas Negeri Padang, Indonesia \\ *Corresponding author: eko.solihin97@gmail.com
}

\begin{abstract}
Abstrak
Kepemimpinan memainkan peran penting dalam pertumbuhan dan ketahanan organisasi atau institusi mana pun, demikian penting halnya dalam manajemen pendidikan karena dampaknya yang lebih besar terhadap pencapaian tujuan pendidikan. Tujuan penelitian ini adalah untuk menganalisis dampak gaya kepemimpinan kepala sekolah terhadap kepuasan pekerjaan dan motivasi guru. Jenis penelitian survei deskriptif. Populasi dalam penelitian ini yaitu kepala sekolah dan guru SMK. Teknik pengambilan sampel menggunakan purposive sampling, sehingga diperoleh jumlah sampel 62 guru dan 1 kepala sekolah. Metode pengumpulan data menggunan kuesioner. Teknik analisis data secara kuantitatif dan kualitatif pengolahan menggunakan SPSS. Berdasarkan hasil analisis menunjukkan bahwa Dari hasil olah data SPSS menunjukkan nilai hasil dampak terhadap kepuasan kerja menunjukan mean value 4,22. Maka dengan demikian gaya kepemimpinan kepala sekolah berdampak signifikan terhadap kepuasan kerja guru. Nilai rata-rata 4,04 untuk pengaruh gaya kepemimpinan kepala sekolah terhadap motivasi kerja guru gaya kememimpinan positif memberi dampak terhadap kepuasan kerja dan motivasi kerja guru. Maka, dapat disimpulkan dampak positif gaya kepemimpinan kepala sekolah terhadap kepuasan kerja dan motivasi guru merupakan pertanda baik bagi individu dan perkembangan SMK. Implikasi penelitian ini dapat meningkatkan kepemimpinan kepala sekolah sehingga kinerja guru menjadi lebih baik.
\end{abstract}

Kata kunci: Gaya Kepemimpinan, Kepuasan, Motivasi Kerja.

\section{Abstract}

Leadership plays an important role in the growth and resilience of any organization or institution, so it is important in education management because of its greater impact on the achievement of educational goals. The purpose of this study was to analyze the impact of the principal's leadership style on job satisfaction and teacher motivation. This type of research is a descriptive survey. The population in this study were principals and vocational school teachers. The sampling technique used purposive sampling, in order to obtain a sample of 62 teachers and 1 principal. Methods of data collection using a questionnaire. Data analysis techniques quantitatively and qualitatively processing using SPSS. Based on the results of the analysis, it is shown that from the results of SPSS data processing, the value of the impact on job satisfaction shows the mean value of 4.22. Thus, the principal's leadership style has a significant impact on teacher job satisfaction. The average value is 4.04 for the influence of the principal's leadership style on the work motivation of teachers. The positive leadership style has an impact on job satisfaction and teacher work motivation. So, it can be concluded that the positive impact of the principal's leadership style on job satisfaction and teacher motivation is a good sign for individuals and the development of SMK. The implication of this research is that it can improve the leadership of the principal so that teacher performance becomes better.

Keywords: Leadership Style, Satisfaction, Work Motivation.

$\begin{array}{ll}\text { History: } & \\ \text { Received } & \text { : 12 April 2021 } \\ \text { Revised } & : 11 \text { Mei } 2021 \\ \text { Accepted } & : 27 \text { Juni } 2021 \\ \text { Published } & \text { : 25 Juli 2021 }\end{array}$

\section{Pendahuluan}

Guru memiliki peran yang besar untuk keberhasilan siswa dan penting dalam menunjang pendidikan di Indonesia (Hapsari et al., 2021; Saifnazarov et al., 2020). Guru merasa puas terhadap pekerjaannya akan menawarkan kualitas pengajar yang lebih tinggi dan pembelajaran yang lebih baik (Putra et al., 2018; Toropova et al., 2021). Kepuasan kerja guru mengacu pada penilai evaluatif optimis dan pesimis yang membuat guru terkait dengan 
pekerjaan sekolah (Liu et al., 2021). Seseorang guru dapat merasa puas dengan beberapa elemen pekerjaan, misalnya, sebuah tingkat kemandirian yang lebih tinggi, demikian pula ketidakpuasan yang disebabkan oleh faktor penentu lain seperti beban berat pekerjaan, tekanan waktu, dan jam yang diperpanjang (Skaalvik \& Skaalvik, 2010; Wolomasi et al., 2019). Kepuasan kerja dianggap sebagai kesenangan dan perasaan optimis yang dihasilkan dari evaluasi pengalaman kerja guru, selain itu guru merasa optimis tentang berbagai komponen tugas yang diberikan dan membuat guru bersemangat bekerja dengan penuh perhatian (Inayatullah \& Jehangir, 2012; Liao et al., 2017). Guru yang termotivasi mampu untuk mengembangkan ikatan yang kuat dengan siswanya dan memotivasi siswanya dan bercita-cita untuk belajar lebih baik. Sebagai akibatnya, penting untuk menyelidiki unsurunsur yang mengahambat motivasi guru (Priyono et al., 2018).

Permasalahan yang terjadi saat ini, kurangnya keterlibatan dalam pengambilan keputusan; tidak adanya peluang karir pertumbuhan dan gaji guru lebih rendah dibandingkan dengan profesional lainya (Adelabu, 2005; Kartini \& Kristiawan, 2019). Motivasi guru mengalami penurunan oleh kepala sekolah yang ikut gaya kepemimpinan laissez faire dan otoriter(Mary \& Bo, 2012) Berdasarkan hasil observasi dan meninjau data ketidakhadiran guru dapat mencerminkan tinggi rendahnya kepuasan kerja dan motivasi kerja guru. Persentase rata-rata tingkat ketidakhadiran guru pada Juli 2020-Desember 2020 mengalami peningkatan yang cukup tinggi yaitu 6,1\% hingga 12,2\% selain itu pada bulan Januari 2021 hingga bulan Februari 2021 mengalami peningkatan yang cukup tinggi yaitu sebesar 4,9\% ke $15,7 \%$. Berdasarkan kuesioner preliminary mengenai gaya kepemimpinan dibagikan kepada 10 guru SMKN 1 GUGUK untuk mengetahui persepsi gaya kepemimpinan di SMKN 1 GUGUK menunjukkan terdapat masalah mengenai kepuasan pekerjaan dan motivasi kerja guru, hal ini terlihat dari jumlah ketidakhadiran guru yang fluaktif meskipun persepsi akan gaya kepemimpinan didominasi oleh pernyataan "setuju" dan "sangat setuju" namun kepuasan kerja dan motivasi kerja guru masih termasuk kedalam kategori yang kurang. Dalam hal ini, salah satu elemen yang bisa menjadi penghambat motivasi dan kepuasan kerja adalah gaya kepemimpinan kepala sekolah yang memimpin dan mengambil keputusan dari pekerjaan mereka.

Kepemimpinan memainkan peran penting dalam pertumbuhan dan ketahanan organisasi atau institusi, demikian pula penting halnya dalam manajemen pendidikan karena dampaknya yang lebih besar terhadap pencapaian tujuan pendidikan (Putra et al., 2018; Wardany, 2020). Kepemimpinan adalah tentang peningkatan dalam organisasi dan mengembangkan pedoman yang disepakati dan berharga untuk organisasi dan mengambil langkah-langkah yang diinginkan untuk memotivasi individu untuk bergerak kearah yang benar (Seashore Louis et al., 2010). Kepemimpinan dalam Lembaga pendidikan adalah prosedur yang kuat di mana seseorang bertanggung jawab atas kerja tim dan mengupayakan usaha kelompok secara dinamis, terlebih lagi menyalurkan dedikasi seluruh anggota tim untuk mencapai tujuan terntu dalam situasi tertentu (Galloway \& Ishimaru, 2015). Kepemiminan dalam konteks ini mengejar kinerja yang lebih baik dalam lembaga pendidikan karena fakta bahwa tidak hanya mengidentifikasi tujuan yang ingin capai dan orangnya bertanggung jawab untuk menerapkannya tetapi berusaha untuk memasukkan karakteristik penguatan yang lebih baik seperti identifikasi. Suasana layanan, membangun kepercayaan, dan pembayaran (Balunywa, 2000; Hinić et al., 2017).

Pentingya gaya kepemimpinan kepala sekolah tidak boleh diremehkan karena penelitian telah menemukan bahwa gaya kepemimpinan di sekolah juga berdampak besar pada pendidikan siswa khususnya dalam keaadan yang rumit (Seashore Louis et al., 2010; Sulfemi, 2020). Keberhasilan utama kegiatan pendidikan bergantung pada gaya kepemimpinan yang dipraktikan di sekolah dan ini bersifat otokratis, demokratis, dan laissez faire (Adeyemi, 2010). Gaya kepemimpinan memberikan dampak positif atau negatif 
terhadap kepuasan kerja yang mengarah pada reaksi sebuah individu terhadap pengalaman kerja, karena berbagai elemen terlibat dalam kepuasan kerja. Faktor-faktor ini terdiri dari gaji, promosi, keuntungan, kolega, lingkungan, keamanan kerja, kinerja dan pekerjaan itu sendiri. Setiap faktor mempengaruhi kepuasan kerja seseorang dengan cara yang berbeda dan banyak yang percaya bahwa keadaan lebih penting daripada faktor lain dalam kepuasan kerja dan pekerja lebih sadar tentang lingkungan tempat bekerja (Liao et al., 2017).

Temuan penelitian sebelumnya menyatakan guru lebih puas bekerja di bawah pemimpin demokratis ketimbang dengan pemimpin otokratis (Armelsa \& Mutiah, 2019; Waters, 2013). Gaya kepemimpinan demokratis adalah gaya utama yang digunakan oleh kepala sekolah di Negeria (Adeyemi, 2010; Ferry \& Ahrens, 2016). Kepala sekolah terlibat dalam gaya kepemimpinan demokratis maka guru tampaknya puas dengan pekerjaan spesifik(Asghar \& Oino, 2017; Oriha, 2018). Lingkungan yang tidak stabil dalam menjamin pencapaian lembaga pendidikan penting untuk menerapkan gaya kepemimpinan yang tepat yang dapat memastikan penerapan prosedur yang dibutuhkan dalam pengajaran (Solihin \& Sukardi, 2020; Torlak \& Kuzey, 2019). Beberapa penelitian menunjukkan gaya kepemimpinan kepala sekolah yang dilihat oleh bawahannya sebagai asset atau kewajiban bagi lembaga, hal tersebut dapat memberikan dampak negatif pada kinerja guru di kelas dan mempengaruhi jenis pergaulan yang mana ada di antara staf dan kepala sekolah. Tujuan penelitian ini untuk menganalisis hubungan antara gaya kepemimpinan kepala sekolah dan motivasi kerja. Adanya penelitian ini sebagai upaya untuk menilai dampaknya terhadap kepuasan kerja guru di SMKN 1 GUGUK.

\section{Metode}

Desain penelitian ini merupakan penelitian survei deskriptif. Desain ini dipilih karena mampu mengumpulkan dan menganalisis data sebagaimana adanya di lapangan tanpa memanipulasi variabel apapun. Populasi dalam penelitian ini yaitu kepala sekolah dan guru berpartisipasi dari SMKN 1 GUGUK. Teknik pengambilan sampel menggunakan purposive sampling, sehingga diperoleh jumlah sampel 62 guru dan 1 kepala sekolah. Data dikumpulkan melalui sumber utama yang diambil dari kuesioner survei yang dirancang untuk penelitian ini. Deskripsi instrumen penelitian berupa kuesioner terstruktur yang merukan alat pengumpulan data untuk mengukur sampel yang besar. Kuesioner digunakan untuk mengumpulan data serta informasi responden dari sekolah karena kuesioner adalah ide untuk semua jenis studi survei. Kuesioner digunakan secara luas dalam pendidikan untuk mengumpulkan data tentang keadaan dan praktik yang ada untuk mengajukan pertanyaan tentang perilaku dan bentuk sikap yang cepat dan akurat. Kuesioner digunakan untuk kepala sekolah serta guru. Setiap kuesioner memiliki dua bagian. Bagian satu dari kuesioner termasuk tanggapan yang berkaitan dengan rincian demografi sedangkan bagian kedua memabahas tentang gaya kepemimpinan, kepuasan kerja dan motivasi kerja. Itu merupakan kuesioner tertutup dan tanggapan diukur dalam peringkat skala lima poin yang termasuk Sangat Setuju (SS), Setuju (S), Tidak Setuju (TS), Sangat Tidak Setuju (STS), dan Belum Memutuskan (BM). Analisis data mengguanakn SPSS versi 26 untuk memerikasa keandalan survei data dari 63 responden.

\section{Hasil dan Pembahasan Hasil Penelitian}

Dari hasil analisis SPSS untuk memeriksa keandalan survei didapatkan nilai Cronbach's Aplha 0,716 yang menunjukkan bahwa data dari 63 responden dapat diandalkan. Kemudian dilanjutkan uji-t sampel pada data yang dikumpulan seperti pada Tabel 1. 
Tabel 2. Ringkasan Hypotheses

\begin{tabular}{lccccc}
\hline \multicolumn{1}{c}{ Hypotheses } & $\begin{array}{c}\text { Mean } \\
\text { Value }\end{array}$ & $\begin{array}{c}\text { P- } \\
\text { value }\end{array}$ & t-value & $\begin{array}{c}\text { Mean } \\
\text { Difference }\end{array}$ & $\begin{array}{c}\text { Empiricial } \\
\text { consclusion }\end{array}$ \\
\hline $\begin{array}{l}\mathrm{H}_{1}: \text { ada dampak yang signifikan } \\
\text { gaya kepemimpinaan kepala }\end{array}$ & & 0,000 & 4,735 & 0,197 & Accepted \\
sekolah terhadap kepuasan kerja \\
guru.
\end{tabular}

Nilai rata-rata 4 atau lebih tinggi merupakan indikasi jelas persetujuan dari hipotesis. Nilai rata-rata dari hipotesis-1 dan hipotesis-2 dalam tabel 2 diatas 4 dan nilai-nilai ini semua telah dibuat diterima/accepted. Nilai mean menunjukkan bahwa semua responden setuju pada pertanyaan-pertanyaan yang disebutkan dalam kuesioner. Nilai signifikan kurang dari 0,05 menunjukkan hasil yang positif, maka berdasarkan mean value, $p$-value, $t$-value, dengan ratarata positif perbedaan kedua hipotesis telah diterima, menunjukkan pentingnya gaya kepemimpinan kepala sekolah pada pekerjaan guru, kepuasan, dan motivasi kerja guru. Hasil dampak terhadap kepuasan kerja menunjukan mean value 4,22 menandakan bahwa guru percaya dan setuju bahwa kepala sekoah menggap guru atau bahwannya sebagai manusia dan gaya kepemimpinan mempengaruhi mereka, memuaskan dan memotivasi guru unruk bekerja lebih banyak untuk diri mereka serta organisasi. Nilai rata-rata 4,04 untuk pengaruh gaya kepemimpinan kepala sekolah terhadap motivasi kerja guru mengungkapkan bahwa guru menganggap gaya kepemimpinan kepala sekolah mereka sebagai motivasi dan mereka mengamati kepala sekolah mereka dengan memegang kualitas kepemimpinan yang tinggi. Hasilnya menunjukkan bahwa guru ditemukan termotivasi dan puas dengan pemimpin demokratis, faktor lain seperti lingkungan kerja, gaji dan beban kerja juga berkontribusi pada tingkat kepuasan yang menginspirasi mereka untuk bekerja dan meraih kesuksesan.

\section{Pembahasan Hasil Penelitian}

Berdasarkan hasil analisis gaya kepemimpinan kepala sekolah memberikan dampak terhadap kepuasan kerja dan motivasi kerja guru. Kepala sekolah SMKN 1 GUGUK percaya demokratis itu adalah strategi yang tepat di sekolah untuk membuat lingkungan yang lebih baik karena departemen yang berbeda berhubungan satu sama lain di sekolah. Dengan demikian, keberhasilkan sekolah terletak pada gotong royong semua pihak dapartemen. Untuk itu guru perlu dimotivasi supaya mengajar dari hati mereka daripada dipaksa bekerja di bawah otoritas yang ketat. Lebih lanjut, pendelegasian tanpa ada tindak lanjut menghasilkan masalah yang bermasalah dan kinerja yang lemah itu akhirnya mempengaruhi reputasi sekolah.

Hipotesis pertama dalam penelitian ini adalah ada dampak yang signifikan gaya kepemimpinaan kepala sekolah terhadap kepuasan kerja guru. Dari hasil olah data SPSS menunjukkan nilai $p$-value $<0,05$. Maka dengan demikian gaya kepemimpinan kepala sekolah berdampak signifikan terhadap kepuasan kerja guru. Gaya Kepemimpinan merupakan suatu cara yang dimiliki oleh seseorang dalam memengaruhi sekelompok orang atau bawahan untuk bekerja sama dan berdaya upaya dengan penuh semangat dan keyakinan untuk mencapai tujuan yang telah ditetapkan (Pradhana, 2019; Priyono et al., 2018; Sulfemi, 2020). Artinya, gaya kepemimpinan dapat menuntun pegawai untuk bekerja lebih giat, lebih 
baik, lebih jujur dan bertanggung jawab penuh atas tugas yang diembannya sehingga meraih pekerjaan dapat diselesaikan dengan baik. Hubungan pimpinan dan bawahan dapat diukur melalui penilaian pekerja terhadap gaya kepemimpinan para pemimpin dalam mengarahkan dan membina para bawahannya untuk melaksanakan pekerjaan(Gulo et al., 2021; Juniarti et al., 2019). Perilaku kepemimipinan atasan yang antara lain terungkap dalam memberikan pertimbangan, membangun struktur inisiasi, dan memberikan penghargaan dapat mendorong terbangunnya kinerja tinggi yang terlihat dalam bentuk penyelesaian tugas, produktivitas kerja, efisiensi biaya, kualitas kerja dan perilaku kerja. Semakin banyak aspek yang sesuai dengan keinginan individu tersebut maka semakin tinggi kepuasan kerjanya(Armelsa \& Mutiah, 2019).

Hipotesis kedua dalam penelitian ini adalah ada dampak yang signifikan gaya kepemimpinaan kepala sekolah terhadap motivasi guru. Dari hasil olah data SPSS menunjukkan nilai $p$-value $<0,05$ bermakna bahwa gaya kepemimpinan kepala sekolah berdampak signifikan terhadap motivasi kerja guru. Motivasi merupakan pemberian daya penggerak yang menciptakan kegairahan kerja seseorang, agar mereka mau bekerjasama, bekerja efektif dan terintegrasi dengan segala daya upayanya untuk mencapai kepuasan. Seseorang yang mempunyai motivasi kerja tinggi akan berusaha melaksanakan tugasnya dengan sekuat tenaga agar pekerjaannya berhasil(Gusviani, 2017; Ristianey et al., 2020). Kemampuan kepala sekola untuk memotivasi orang lain supaya mampu mengikuti dan mewujudkan visi organisasi(Kartini \& Kristiawan, 2019).

Temuan penelitian sebelumnya menyatakan kepuasan kerja guru mendapat hasil bahwa terdapat pengaruh positif gaya kepemimpinan terhadap kepuasan kerja guru (Armelsa \& Mutiah, 2019; Bulan et al., 2018; Sari et al., 2020). Hasil hipotesis kedua sejalan dengan penelitian dari Intan Mar'atu Solihat (2020) di SMAN 3 Purwakarta menyimpulkan gaya kepemimpinan secara parsial berpengaruh signifikan terhadap motivasi kerja guru (Gulo et al., 2021; Intan Mar'atu Solihat, 2020; Mengesha, 2015). Hasil kuesioner dan hipotesis menunjukkan dan menjawab pertanyaan penelitian bahwa guru positif kepada kepala sekolah mereka dan menghargai karena mempromosikan kepemilikan di dalam sekolah, para guru juga berpartisipasi dalam prosedur perencanaan dan mereka diizinkan untuk membuat keputusan di kelas tanpa kekuatan apa pun dan izin dari kepala sekolah. Guru juga SMKN 1 GUGUK setuju bahwa mereka mendekati kepala sekolah sangat mudah di sekolah dan selalu siap mengikuti perubahan manajemen yang dibutuhkan di sekolah. Dari pembahasan di atas dapat dipahami bahwa gaya kepemimpinan kepala sekolah merupakan salah satu faktor penentu kepuasan guru dan motivasi guru. Hal tersebut dapat dilihat dari kepala sekolah mengupayakan pelaksanaan pencapaian tujuan pendidikan dengan memenuhi kebutuhan guru dan memberikan motivasi kerja di SMKN 1 GUGUK. Kajian ini dapat dijadikan sebagai evaluasi dalam meningkatkan kepemimpinan guru dan kinerja guru selanjutnya, sehingga peningkatan mutu pendidikan dapat terlaksana dengan optimal.

\section{Simpulan}

Berdasarkan hasil analisis dan pembahasan yang telah dilakukan maka penulis membuat kesimpulan bahwa kepala sekolah menerapakan gaya kepemimpinan demokratis di SMKN 1 GUGUK dan Gaya kepemimpinan kepala sekolah berdampak positif secara signifikan terhadap kepuasan perkerjaan guru serta gaya kepemimpinan kepala sekolah berdampak positif dan signifikan terhadap motivasi kerja guru SMKN 1 GUGUK. Dampak positif gaya kepemimpinan kepala sekolah terhadap kepuasan kerja guru dan motivasi kerja merupakan pertanda baik bagi individu dan perkembangan Sekolah. Penelitian ini memiliki beberapa hal yang menjadi keterbatasan, diantaranya objek penelitian ini hanya satu sekolah menengah kejuruan serta waktu penelitian yang terbatas dan jumlah responden 93 orang. 
Penulis mengusulkan beberapa elemen untuk praktisi dan penelitian selanjutnya supaya dapat memperluas objek penelitian tidak hanya 1 sekolah dan memperluas responden di sekolah. Kepuasan dan motivasi berparsipasi dalam pengambilan keputusan yang mengarah pada kinerja yang lebih baik untuk guru dan untuk SMKN 1 GUGUK.

\section{Daftar Rujukan}

Adelabu, M. (2005). Teacher motivation and incentives in Nigeria. London: DFID, December.

Adeyemi, T. O. (2010). Principals ' leadership styles and teachers' job performance in senior secondary schools in Ondo State , Nigeria. Journal of Education, 2(July), 83-91.

Armelsa, D., \& Mutiah, T. (2019). Pengaruh Kepemimpinan dan Kepuasan Kerja Terhadap Kinerja Guru SMP Negeri Kecamatan Setu Kabupaten Bekasi. Cakrawala-Jurnal Humaniora, 19(1), 95-99.

Asghar, S., \& Oino, I. (2017). Munich Personal RePEc Archive Leadership Styles and Job Satisfaction Leadership Styles and Job Satisfaction. 91137.

Balunywa, W. S. (2000). A handbook of business management. Ugandan Press.

Bulan, S., Chandra, T., \& Komara, A. H. (2018). The Efect Of Leadership Styles, Motivation, And Commitment On Work Satisfaction And Primary Teachers'Performance In Rimba Sub-District Of Rokan Hilir. 3(2), 156-170.

Ferry, L., \& Ahrens, T. (2016). Leadership style and job satisfaction in higher education institutions. International Journal of Educational Management, 30, 140-164.

Galloway, M. K., \& Ishimaru, A. M. (2015). Radical Recentering: Equity in Educational Leadership Standards. Educational Administration Quarterly, 51(3), 372-408. https://doi.org/10.1177/0013161X15590658.

Gulo, S., Nadeak, B., Tampubolon, H., Administrasi, M., Universitas, P., \& Indonesia, K. (2021). Pengaruh Gaya Kepemimpinan Kepala Terhadap Kinerja Guru Di Smp SeNias Barat. 14(1), 1-12.

Gusviani, E. (2017). Analisis Kemunculan Sikap Spiritual Dan Sikap Sosial Dalam Kegiatan Pembelajaran Ipa Kelas Iv Sd Yang Menggunakan Ktsp Dan Kurikulum 2013. EduHumaniora | Jurnal Pendidikan Dasar Kampus Cibiru, 8(1), 96. https://doi.org/10.17509/eh.v8i1.5127.

Hapsari, F., Desnaranti, L., \& Wahyuni, S. (2021). Peran Guru dalam Memotivasi Belajar Siswa selama Kegiatan Pembelajaran Jarak Jauh. Research and Development Journal of Education, 7(1), 193. https://doi.org/10.30998/rdje.v7i1.9254.

Hinić, D., Grubor, J., \& Brulić, L. (2017). Followership styles and job satisfaction in secondary school teachers in serbia. Educational Management Administration and Leadership, 45(3), 503-520. https://doi.org/10.1177/1741143215623787.

Inayatullah, A., \& Jehangir, P. (2012). Teacher's job performance: the role of motivation. Abasyn Journal of Social Sciences, 5(2), 78-99.

Intan Mar'atu Solihat, F. P. S. (2020). the Effect of Leadership Style on Work Motivation in Teachers of Sman 3. 7(1), 320-327.

Juniarti, E., Ahyani, N., \& Ardiansyah, A. (2019). Pengaruh Kepemimpinan Kepala Sekolah Dan Efikasi Diri Guru Terhadap Kinerja Guru. Reslaj : Religion Education Social Laa Roiba Journal, 1(3), 193-199. https://doi.org/10.47467/reslaj.v1i2.108.

Kartini, D., \& Kristiawan, M. (2019). Pengaruh Tunjangan Profesi dan Motivasi Kerja Terhadap Kinerja Guru. Jurnal Manajemen Pendidikan, 6(1), 25-33. https://doi.org/10.24246/j.jk.2019.v6.i1.p25-33. 
Liao, S. S., Hu, D. C., Chung, Y. C., \& Chen, L. W. (2017). LMX and employee satisfaction: mediating effect of psychological capital. Leadership and Organization Development Journal, 38(3), 433-449. https://doi.org/10.1108/LODJ-12-2015-0275.

Liu, Y., Bellibaş, M. Ş., \& Gümüş, S. (2021). The Effect of Instructional Leadership and Distributed Leadership on Teacher Self-efficacy and Job Satisfaction: Mediating Roles of Supportive School Culture and Teacher Collaboration. Educational Management Administration and Leadership, 49(3), 430-453. https://doi.org/10.1177/1741143220910438.

Mary, N. G. F., \& Bo, O. (2012). Leadership style factors that influence motivation of preschool teachers in public pre-schools in Embu North District, Embu County, Kenya.

Mengesha, A. H. (2015). Impact of leadership approaches on employee motivation: An empirical investigation in Haramaya University. AshEse Journal of Business Management, 1(3), 28-038.

Oriha, T. M. (2018). Leadership Styles of Head Teachers as a Determinant of Teachers Job Performance (Doctoral dissertation). Godfrey Okoye University.

Pradhana, A. (2019). Pengaruh Gaya Hidup Dan Electronic Word Of Mouth Terhadap Keputusan Pembelian Gadget (Telepon Pintar) (Studi pada Mahasiswa Administrasi Bisnis FISIP UNILA). Journal of Chemical Information and Modeling, 53(9), 16891699. https://doi.org/10.1017/CBO9781107415324.004.

Priyono, B. H., Qomariah, N., \& Winahyu, P. (2018). Pengaruh Gaya Kepemimpinan, Motivasi Guru Dan Lingkungan Kerja Fisik Terhadap Kinerja Guru Sman 1 Tanggul Jember. Jurnal Manajemen Dan Bisnis Indonesia, 4(2), 144. https://doi.org/10.32528/jmbi.v4i2.1758.

Putra, C. A. A., Yudana, M., \& Natajaya, N. (2018). Hubungan motivasi berprestasi, prilaku kepemimpinan kepala sekolah dan etos kerja dengan kinerja guru. Jurnal Penelitian Dan Pengembangan Sains Dan Humaniora, 1(1), 14-20. https://doi.org/10.23887/jppsh.v1i1.12925.

Ristianey, F., Harapan, E., \& Destiniar, D. (2020). Pengaruh Sertifikasi Guru Dan Motivasi Kerja Terhadap Kinerja Guru. JMKSP (Jurnal Manajemen, Kepemimpinan, Dan Supervisi Pendidikan), 6(1), 1310-1317. https://doi.org/10.31851/jmksp.v6i1.3950.

Saifnazarov, I., Abdullahanova, G., Alimatova, N., \& Kudratova, U. (2020). The main trends of increasing the role of the teacher in the innovative development of uzbekistan. International Journal of Advanced Science and Technology, 29(5), 1771-1773.

Sari, Y., Khosiah, S., Maryani, K., Sultan, U., \& Tirtayasa, A. (2020). Pengaruh Gaya Kepemimpinan Demokratis Kepala Sekolah Terhadap Kinerja Guru PAUD. Jurnal Golden Age, 4(01), 20-29. https://doi.org/10.29408/jga.v4i01.1874.

Seashore Louis, K., Leithwood, K. a, Wahlstrom, K. L., \& Anderson, S. E. (2010). Learning from Leadership: Investigating the Links to Improved Student Learning. ERS Informed Educator, 2012(10/7/2012), 1-11.

Skaalvik, E. M., \& Skaalvik, S. (2010). Teacher self-efficacy and teacher burnout: A study of relations. Teaching and Teacher Education, 26(4), 1059-1069. https://doi.org/10.1016/j.tate.2009.11.001.

Solihin, E., \& Sukardi, S. (2020). Pengaruh Penerapan Sistem Control Valve Cooler 1 Berbasis Microcontroller ATmega 2560 Terhadap Moisture Pakan After Mixing dengan Bagging Off di PT. Japfa Comfeed Indonesia, Tbk. Unit Padang. JTEV (Jurnal Teknik Elektro Dan Vokasional), 6(2), 80. https://doi.org/10.24036/jtev.v6i2.108549.

Sulfemi, W. B. (2020). Pengaruh Rasa Percaya Diri Dan Gaya Kepemimpinan Kepala Sekolah Terhadap Kinerja Guru. Nidhomul Haq: Jurnal Manajemen Pendidikan Islam, 5(2), 157-179. https://doi.org/10.31538/ndh.v5i2.557. 
Torlak, N. G., \& Kuzey, C. (2019). Leadership, job satisfaction and performance links in private education institutes of Pakistan. International Journal of Productivity and Performance Management, 68(2), 276-295. https://doi.org/10.1108/IJPPM-05-20180182.

Toropova, A., Myrberg, E., \& Johansson, S. (2021). Teacher job satisfaction: the importance of school working conditions and teacher characteristics. Educational Review, 73(1), 71-97. https://doi.org/10.1080/00131911.2019.1705247.

Wardany, D. K. (2020). Kontribusi Kepemimpinan dan Kompetensi Profesional Terhadap Kinerja Guru. Jurnal Madinasika Manajemen Dan Keguruan, 1(2), 73-82.

Waters, K. K. (2013). The relationship between principals' leadership styles and job satisfaction as perceived by primary school teachers across NSW independent schools. International Research Journal of Education, 233.

Wolomasi, A. K., Werang, B. R., \& Asmaningrum, H. P. (2019). Komitmen Kerja dan Pengaruhnya Terhadap Semangat dan Kepuasan Kerja Guru Sekolah Dasar. Musamus Journal of Primary Education, 2(1), 13-23. https://doi.org/10.35724/musjpe.v2i1.1572. 